American Journal of Immunology 4 (4): 43-50, 2008

ISSN 1553-619X

(C) 2008 Science Publications

\title{
Voltage-Gated Channels as Causative Agents for Epilepsies
}

\author{
${ }^{1}$ Mutasem Abuhamed, ${ }^{1}$ Xiao Bo, ${ }^{2}$ Kun Xia, ${ }^{1}$ Yi Fang and ${ }^{1}$ LiLi Long \\ ${ }^{1}$ Department of Neurology, Xiangya Hospital, \\ Central South University, Changsha, Hunan, PR China \\ ${ }^{2}$ National Lab of Genetics, Central South University, Changsha, Hunan, PR China
}

\begin{abstract}
Problem statement: Epilepsy is a common neurological disorder that afflicts $1-2 \%$ of the general population worldwide. It encompasses a variety of disorders with seizures. Approach: Idiopathic epilepsies were defined as a heterogeneous group of seizure disorders that show no underlying cause .Voltage-gated ion channels defect were recognized etiology of epilepsy in the central nervous system. The aim of this article was to provide an update on voltage-gated channels and their mutation as causative agents for epilepsies. We described the structures of the voltage-gated channels, discuss their current genetic studies, and then review the effects of voltage-gated channels as causative agents for epilepsies. Results: Channels control the flow of ions in and out of the cell causing depolarization and hyper polarization of the cell. Voltage-gated channels were classified into four types: Sodium, potassium calcium ands chloride. Voltage-gated channels were macromolecular protein complexes within the lipid membrane. They were divided into subunits. Each subunit had a specific function and was encoded by more than one gen. Conclusion: Current genetic studies of idiopathic epilepsies show the importance of genetic influence on Voltage-gated channels. Different genes may regulate a function in a channel; the channel defect was directly responsible for neuronal hyper excitability and seizures.
\end{abstract}

Key words: Epilepsy, ion channel proteins, voltage-gated channels

\section{INTRODUCTION}

Epilepsy is defined as a group of diseases caused by a non-con-trolled discharge of neurons of either the whole cortex (generalized epilepsies) or localized brain areas (partial epilepsies) that show no underlying cause other than a possible inherited predisposition ${ }^{[1]}$. The genetic basis for two idiopathic epilepsies has now been pinpointed to specific ion channel proteins for two different potassium-channel genes (KCNQ2, MIM 602235 and KCNQ3, MIM 602232 $)^{[2,3]}$ or sodium channel subunits (SCN2A, OMIM 601219) ${ }^{[4-6]}$. Voltages gated Channels are membranous structures formed by aggregated proteins and contain aqueous central pores that allow the passage of ions. Channels control the flow of ions in and out of the cell causing depolarization and hyper polarization of the cell. Neurotoxins selectively inactivate different sites of the ion channel thus allowing both the identification of channel components and the determination of their functions $^{[7]}$. In this review, we consider reports that focus on structure and function of the voltage-gated channel proteins and their mutation.

\section{MATERIALS AND METHODS}

Voltage-gated sodium channels: The voltage-gated sodium channels are integral membrane proteins essential for the generation and propagation of action potentials in excitable tissues . They are usually made up of $\alpha . \beta-1$ and $\beta-2$ subunits. The $\alpha$-subunit is the major part of channel pore, containing four homologous domains. Each domain contains six $\alpha$ helix transmembrane segment (S1-S6). The S4 segment is rich of positive charge amino acid residues, acting as the channel-activating electrical sensor receptor. $\beta-1$ and $\beta-2$ are both auxiliary subunits, which have the regulating function. The gene mutation of channels can cause the structure and function abnormality of corresponding channels' protein, which cause the abnormality of neuron excitability and the epilepsy. There are two GEFS+-associated mutation (R1648H, $\mathrm{R} 1657 \mathrm{C})$ affecting the S4 segment of domain $\chi$. The $\mathrm{R} 1648 \mathrm{H}$ mutation affects a positive residue in the middle of D4/S4 and exhibit similar slope conductance but had an increased probability of late reopening and a

Corresponding Author: Xiao Bo, Department of Neurology, The First Affiliated Xiangya Hospital,Central South University, Changsha, Hunan, PR China 
sub fraction of channels with prolonged open times. while $\mathrm{R} 1657 \mathrm{C}$ affects the innermost positive residue in this voltage-sensing segment and exhibits conductance, open probability, mean open time and latency to first opening similar to WT channels but reduced whole cell current density, suggesting decreased number of functional channels at the plasma membrane ${ }^{[8]}$. The idiopathic epilepsy syndrome to be mapped from a single pedigree, Generalized epilepsy with febrile seizures plus (GEFS + ), was reported exactly ten years ago by ${ }^{[9]}$ and was a classic example of genetic heterogeneity with so far at least 4 mutations in different gene loci producing the same phenotype and the long-awaited cloning of this gene eloquently illustrates how genetic analysis of epilepsy is contributing not only to our understanding of the disease but also to the basic molecular neurobiology of the brain. GEFS syndrome is caused by mutation of the sodium channel b1 subunit gene located on chromosome 19q13.1. They elegantly demonstrated in Xenopus laevis oocytes that this mutation interferes with the ability of the channel b-1 subunit to modulate gating kinetics, possibly leading to membrane hyper excitability. Baulac et al.$^{[10]}$ have identified a family with with GEFS1, by linkage analysis, that the affected gene map locus was in the region of 2q21-q33. Escayg et al. ${ }^{[11]}$ describe two separate families and found the abnormality of the gene map locus on chromosome 2q24. Another family with GEFS1 was found mapped to chromosome $2 \mathrm{q} 23-24^{[12]}$. These genes encode different isoforms of the subunit of the sodium channel. Other families have been studied and other gene loci have been detected. The human b1 mutant subunit prolongs neuronal depolarization under steadystate conditions when co-expressed in vitro with a rat brain sodium channel a subunit RBII; however, there is still little insight into how the sodium channel defect gives rise to the phenotypically diverse seizure patterns seen within a single GEFS+ pedigree. The amino acid exchange resulting from the mutation interferes with the ability of the subunit to modulate the channel-gating kinetics of $\mathrm{Na}$-channel a subunit, which is consistent with loss of function ${ }^{[9]}$.

Seizures in some affected individuals also occurred during a febrile episode, but most of these events were found to persist beyond the age of 6 years, which is the commonly used diagnostic cut-off for the clinical syndrome classified as febrile seizures. In febrile seizures, $90 \%$ of cases show seizures in the first 3 months of life and less than $10 \%$ develop afebrile seizures at a later $\operatorname{age}^{[4]} \mathrm{A}$ new candidate sodium channel gene for epilepsy was also proposed after the discovery that it is selectively expressed in the limbic system of the brain, giving new meaning to the term 'positional cloning'. The mRNA for sodium channel SCN5A gene, which is localized to chromosome 3p24, was expressed in the brain piriform cortex and amygdala using in situ hybridization and PCR techniques. These limbic networks have been long known to possess the lowest threshold for epileptogenesis of any brain region ${ }^{[3]}$.

Voltage-gated potassium channels: Voltagedependent potassium channel is one of the most important ionic pores for generation and propagation of the action potential. Since specific genes coding for this channel is expressed in the central nervous system, it could be expected that a mutation in these genes may be at the origin of unbalance between excitation and inhibition and thus could cause epilepsy. Voltage-gated potassium $(\mathrm{K}+)$ channels represent the most heterogeneous class of ion channels with respect to kinetic properties, regulation and pharmacology. In neuronal cells, voltage-gated $\mathrm{K}+$ channels regulate excitability by controlling action potential duration, subthreshold electrical properties and responsiveness to synaptic inputs. Voltage-gated potassium channels are multi-subunit proteins with the core channel consisting of a tetramer of a-subunits, which surround a $\mathrm{K}+$ selective pore. Current understanding of the mechanisms that govern $\mathrm{K}+$ channel assembly is incomplete. So far, two types of domains involved in $\mathrm{K}+$ channel assembly have been described. In Shakerrelated $\mathrm{K}+$ channels an aminoterminal domain (T1) was found important for channel assembly. In contrast, carboxy-terminal sequences are required for assembly of functional ether-a'-go-go (eag) ${ }^{[13]}$ and $\mathrm{KCNQ}(\mathrm{Kv} 7)$ channels ${ }^{[14]}$.A potassium channel mutation that is linked with epilepsy provides a partially penetrant human epilepsy phenotype with variable regional brain excitability alterations. In Leppert et al. ${ }^{[15]}$, a large pedigree displaying a variety of seizure phenotypes, was linked to a point mutation of the potassium channel EBN1 gene located on chromosome20q13.2 and EBN2 gene located on $8 \mathrm{q} 24$, leading to identification of the KCNQ2 and KCNQ3 ion channels. These proteins are similar to the 6TM domain KCNQ1 channel that is mutated in one variant of the cardiac long QT syndrome. The KCNQ2 and KCNQ3 are believed to interact as heterodimers expressed diffusely in brain and persist in adulthoodt, although seizures associated with BFNC typically disappear by 6 months of age. The 
question that why KCNQ2/ KCNQ3 mutation causes epileptic paroxysm only appears in the newborn time is still discussing. One kind of explanations is the brain in the developing period compares to the mature period is easier to have the convulsion. Another kind of possibility explanation is the presentation of KCNQ2/ KCNQ3 has the small difference in the brain growing process. At first several days or weeks after birth, KCNQ is on the dominant position in the central nervous system-----the KCNQ potassium channel possibly in the higher expression level while other voltage-gated potassium channels in the lower. In addition, the human brain possibly only in some specific time expresses KCNQ2 or KCNQ3.

Co-expression of KCNQ2 and KCNQ3 leads to a large increase of the potassium current. KCNQ2 and 3 are thought to contribute synergistically to the formation of M-current. M-current regulates the subthreshold electric excitability of neurons. This implies that a slight impairment of the M-current converts the firing properties of neurons from phasic to tonic, without affecting any other electrophysiological properties such as the slow after-hyperpolarization ${ }^{[16]}$. There is a new evidence of members of the Drosophila ether-a-go-go potassium channel gene subfamily for this clinical entity, called 'benign infantile epilepsy syndrome, may contribute to the mammalian $\mathrm{M}$ current $^{[16,17]}$, suggesting that there may be additional candidate $\mathrm{K}+$ channel genes involved in epilepsy, one of which, KCNJ1O, exhibits a potentially important polymorphism with regard to fundamental aspects of seizure susceptibility. The KCNJ10 gene is located lq22-q23, found in almost mammalian and code potassium inwardly rectifying channel (Kir). Kir is possible cushioning potassium concentration of cerebrum neuroglia cell. Deletion of KCNJ1O as a seizure susceptibility gene that code for inward rectifier potassium ion channels imparts protection against seizures results in spontaneous seizures and increased seizure susceptibility ${ }^{[18]}$.

Recently, about thirty Q2 and three Q3 mutations have been discovered in families affected by $\mathrm{BFNC}^{[19]}$. Those mutations whose functional consequences have been investigated ${ }^{[20]}$ cause a small $(<25 \%)$ reduction in the maximal current carried by the Q2/Q3 channels; only two Q2 mutations caused a more dramatic current reduction, consistent with a dominant-negative effect ${ }^{[19]}$. A large fraction of BFNC-causing mutations in Q2 are represented by insertions or deletions leading to changes in the primary sequence of the long cytosolic $\mathrm{C}$ terminus, where relevant sites have been detected for functional regulation. In fact, specific sequences within this region (the so-called "subunit interaction domain" or sid) ${ }^{[21]}$ dictate the specificity of KCNQ subunit assembly and provide sites where other signaling proteins such as calmodulin ${ }^{[22]}$ and protein kinases and kinase-anchoring proteins ${ }^{[23]}$ interact with KCNQ subunits and modulate channel activity.

Voltage-gated calcium channels: Voltage-gated calcium channels are key mediators of calcium entry into neurons in response to membrane depolarization. Calcium influx via these channels mediates a number of essential neuronal responses, such as the activation of calcium-dependent enzymes, gene expression ${ }^{[24,25]}$, the release of neurotransmitters from presynaptic sites ${ }^{[26-28]}$ and the regulation of neuronal excitability ${ }^{[29]}$. Voltagegated calcium channels are heteromultimers composed of an $a_{1}$ subunit and three auxiliary subunits, $a_{2}-d, b$ and g. The $a_{1}$ subunit forms the ion pore and possesses gating functions and, in some cases, drug binding sites. Ten $a_{1}$ subunits have been identified, which, in turn, are associated with the activities of the six classes of calcium channels. L-type channels have $\mathrm{a}_{1 \mathrm{C}}$ (cardiac), $\mathrm{a}_{1 \mathrm{D}}$ (neuronal/endocrine), $\mathrm{a}_{1 \mathrm{~S}}$ (skeletal muscle) and $\mathrm{a}_{1 \mathrm{~F}}$ (retinal) subunits,and typically found on cell bodies where they participate, among other functions, in the activation of calcium-dependent enzymes and in calcium-dependent gene transcription events ${ }^{[24,30]}, \mathrm{N}-$ type channels have $\mathrm{a}_{1 \mathrm{~B}}$ subunits, and produce inactivating currents that are selectively and potently inhibited by conotoxins GVIA and MVIIA; P-and Qtype channels concentrated at presynaptic nerve terminals where they are linked to the release of neurotransmitters ${ }^{[31,32]}$ and have $\mathrm{a}_{1 \mathrm{~A}}$ subunits and T-type channels have $\mathrm{a}_{1 \mathrm{G}}, \mathrm{a}_{1 \mathrm{H}}$ and $\mathrm{a}_{1 \mathrm{II}}$ subunits. In the context of neurotransmitter release, N-type and P/Q-type channels do not appear to be created equally, as N-type channels tend to support inhibitory neurotransmission, whereas the P/Q-type channels have more frequently been linked to the release of excitatory neurotransmitters but can also support inhibitory release ${ }^{[33-36]}$. R-type channels rapidly inactivating and activate at somewhat more hyperpolarized potentials compared with the other HVA calcium channel subtypes. The $a_{1}$ subunits each have four homologous domains (I-IV) that are composed of six transmembrane helices. The fourth transmembrane helix of each domain contains the voltage-sensing function. The four $a_{1}$ domains cluster in the membrane to form the ion pore. The principal pore-forming $\alpha 1$ subunits of calcium channels are have been identified into three major classes: Cav1, Cav2 and Cav3.Among the Cav2 family, alternate splice isoforms of Cav2.1 encode P-and Q-type channels ${ }^{[37]}$, the Cav3 family 
represents three different types of T-type channels (i.e., Cav3.1, Cav3.2 and Cav3.3) with distinct kinetic properties $^{[38]}$. The b-subunit is localized intracellularly and is involved in the membrane trafficking of $a_{1}$ subunits. The g-subunit is a glycoprotein having four transmembrane segments. The $a_{2}$ subunit is a highly glycosylated extracellular protein that is attached to the membrane-spanning $\mathrm{d}$-subunit by means of disulfide bonds. The $a_{2}$-domain provides structural support required for channel stimulation, while the $\mathrm{d}$ domain modulates the voltage-dependent activation and steadystate inactivation of the channel. A growing body of evidence firmly establishes $\mathrm{P} / \mathrm{Q}$-type and T-type channels as important contributors to seizure genesis through modulation of neuronal properties that act to shape network function, whereas other types of calcium channels do not appear to contribute to the development of seizure activity.

T-type channels: T-type channels have always been likely candidates due to their eminent presence in cortical and thalamic structures and their established physiological role in modulating neuronal firing. In the Genetic Absence Epilepsy Rat from Strasbourg (GAERS) model an Increase in T-type currents in reticular neurons has been reported after the second postnatal week ${ }^{[39]}$. This increase in T-type currents is putatively mediated by elevated $\mathrm{Ca}_{\mathrm{v}} 3.2$ expression in reticular neurons, which as the animal develops to exhibit absence like seizures, is also accompanied by elevated expression of $\mathrm{Ca}_{\mathrm{v}} 3.1$ in relay neurons. The causal connection between increased T-type channel activity and subsequent development of seizures remains to be established. It is conceivable that developmental causes involving either modulation of the channels, their redistribution with other isoforms and alternate splicing may be contributing factors.

Recent studies involving t-type $\left(\mathrm{Ca}_{\mathrm{v}} 3.1\right)$ KnockOut (KO) mice have provided additional role of T-type channels in absence like seizure episodes ${ }^{[40]}$. Ablation of the $\mathrm{Ca}_{\mathrm{v}} 3.1$ gene abolishes rebound spiking in dissociated adult thalamocortical neurons but does not alter their ability to fire tonically. The direct link involving T-type channels and the generalized spikewave epilepsies in humans was recently established. A number of missense mutations have been identified in the Cav3.2 calcium channel gene in patients diagnosed with childhood absence epilepsy and other forms of idiopathic generalized epilepsy. Several of these mutations were found to result in small changes in the gating characteristics of both rat and human Cav3.2 channels in a manner consistent with a gain of function. Specifically, some of the mutations resulted in a hyperpolarizing shift in the voltage dependence of activation, while others resulted in increased channel availability due to decreased steady-state inactivation. However, the majority of the mutations did not significantly affect the biophysical characteristics of the channel $^{[41]}$. A recent study ${ }^{[42]}$ has demonstrated that the CACNA1H (Cav3.2) T-type calcium channel gene can undergo extensive alternative gene splicing. This might be a possible mechanism by which these mutations could affect seizure threshold in certain neurons.

P/Q-type calcium channels: Evidence from rat and mouse models of absence epilepsy, knockout mice and characterization of functional effects of mutations found in patients all point to the fact that inhibition of $\mathrm{P} / \mathrm{Q}$-type channel activity somehow alters neurons and neuronal networks to result in seizure activity. This may also apply for variants of ancillary subunits that can act to reduce P/Q-type channel function. There are several potential avenues by which reduced $\mathrm{P} / \mathrm{Q}$-type channel activity could affect network properties that give rise to seizure activity. First, P/Q-type channel defects preferentially affect excitatory synaptic transmission. Second, P/Q-type channel activity is directly linked to calcium-dependent gene transcription via the CREB (cAMP-response element binding protein) pathway ${ }^{[36,43]}$ and therefore, reduced $\mathrm{P} / \mathrm{Q}$-type channel activity may compromise appropriate gene regulation and expression. Finally, T-type calcium channel activity appears to be increased in at least four different mouse models of absence epilepsy (i.e., Cav2.1 KO, tg, lh, stg $)^{[42]}$; therefore, it is conceivable that the epileptic phenotypes associated with compromised P/Q-type channel function may arise indirectly from enhanced neuronal excitability mediated by $\mathrm{T}$ types.

Voltage-gated Cl-channels: Voltage-gated Clchannels are implicated in GABA (A) transmission and mutations in these channels have been described in some families with juvenile myoclonic epilepsies, epilepsy with grand mal seizures on awakening or juvenile absence epilepsy. Hyperpolarisation-activated cation channels have been implicated in spike-wave seizures and in hippocampal epileptiform discharges. The Cl-ionophore of the GABA (A) receptor is responsible for the rapid post-PDS hyperpolarisation, it has been involved in epileptogenesis both in animals and humans and mutations in these receptors have been found in families with juvenile myoclonic epilepsy or generalised epilepsy with febrile seizures plus; enhancement of GABA (A) inhibitory transmission is the primary mechanism of benzodiazepines and 
phenobarbital and is a mechanistic approach to the development of novel AEDs such as tiagabine or vigabatrin. Though more and more ion channel mutations are being identified in genetic studies, their small incidence is still indicative of the presence of undiscovered mutations or other causative mechanisms ${ }^{[44]}$. Understanding wild-type channel function during epileptic activity and performing analysis of the biophysical properties of mutant channels may also provide vital insights into the remaining epilepsies and discover targets for future anti-epileptic drugs.

\section{RESULTS AND DISCUSSION}

Epilepsy is a disorder of recurrent spontaneous seizures affecting about $4 \%$ of individuals over their lifetimes and encloses a variety of disorders with electroencephalogram paroxysms. In spite of a genetic component in the pathogenesis of epilepsy, the molecular mechanisms of this syndrome remain poorly understood $^{[45]}$. Recently, several paroxysmal neurological disorders were considered to be caused by abnormal channel. Focusing on idiopathic epilepsy, long-lasting changes in the expression levels of voltagegated channels have been found to promote pathological brain activity, the discovery of the underlying Channel defects in these idiopathic epilepsies has several practical implications for the practicing neurologist. First, the identification of specific ion channel defects has provided insights on the pathogenesis of seizures, has identified molecular targets for the rational design of therapeutic intervention and can be used to more accurately classify patients into specific categories. This segregation is important for providing patients with a more accurate diagnosis.

Recent researches of epilepsy support that at least some of the idiopathic epilepsies must be considered as channelopathies. The channelopathy seems to explain issues related to epilepsy, i.e., neuronal hyperexcitability and dominant inheritance with various penetrance ${ }^{[45]}$. The imbalance between inhibitory and excitatory neurotransmission precipitates abnormally frequent electrical discharges in neurons. Voltage gated channels consist of several subunits and function as a hetero-multimer. Coexistence of deficient subunits in such multimers induces a renowned genetic phenomenon, i.e., the dominant negative effect. Voltage-gated sodium and potassium channels are the most common ionic pores for generation and propagation of the action potential however it is less clear how mutations of calcium and chloride channels and nicotinic receptors cause epilepsy ${ }^{[46]}$. Mutational analyses of voltage-gated sodium (SCN1A, SCN1B) channels and potassium channel subunits (KCNQ2, KCNQ3) in GEFS1 and BFNC, suggest that allelic and non-allelic genetic heterogeneity is important in these two epileptic syndromes. As suggested by recent results, the causal gene remains unknown in most GEFS1 pedigrees. In the same way, other genes are probably involved in BFNC, since only six KCNQ2 mutations were observed in $23 \mathrm{BFNC}$ probands. The major candidate genes for both of these benign familial epilepsies are the other sodium and potassium channel genes. Recently, a sodium channel polymorphism was shown to associate with antiepileptic drug dosage ${ }^{[45]}$. Interestingly, it affects splicing of sodium channels and alters their biophysical properties that provide a possible mechanistic explanation for the difference in anti-epileptic drug responsiveness or tolerability.

\section{CONCLUSION}

In conclusion the elucidation of the $\mathrm{Na}+, \mathrm{K}+, \mathrm{Cl}+$ and $\mathrm{Ca} 2+$ channels defects of epilepsies, leads to better understanding of the pathophysiology of epilepsies. The importance of ionic channels as cause of epilepsies was demonstrated with the identification of the association between the epilepsy and mutations in genes coding for ion channel subunits.

\section{ACKNOWLEDGEMENT}

Special thanks to Hanan Ghazi Salem for her insightful comments and advice in the preparation of this review article.

\section{REFERENCES}

1. Steinlein, O.K. and J.L. Noebels, 2000. Ion channels and epilepsy in man and mouse. Curr. Opin. Genet. Dev., 10: 286-291. DOI: 10.1016/S0959-437X(00)00079-4.

2. Engel, J., 2001. A proposed diagnostic scheme for people with epileptic seizures and with epilepsy: Report of the ILAE Task Force on classification and terminology. Epilepsia, 42: 796-803. DOI: 10.1046/j.1528-1157.2001.10401.x.

3. Pereira, S., P. Roll, J. Krizova, P. Genton, M. Brazdil, R. Kuba, P. Cau, I. Rektor and P. Szepetowski, 2004. Complete loss of the cytoplasmic carboxyl terminus of the KCNQ2 potassium channel: A novel mutation in a large Czech pedigree with benign neonatal convulsions or other epileptic phenotypes. Epilepsia, 45: $\quad 384-390 . \quad$ DOI: $\quad 10.1111 / \mathrm{j} .0013-$ 9580.2004.47703.x. 
4. Xiao, B., F.Y. Deng, G. Xiong, K. Wang, J. Zhang, X.D. Chen, Y.Z. Liu and H.W. Deng, 2005. Clinical and genetic study on a new Chinese family with benign familial infantile seizures. Eur. J. Neurol., 12: 344-349. DOI: $10.1111 /$ j.14681331.2004.00989.x.

5. Berkovic, S.F., S.E. Heron, L. Giordano, C. Marini, R. Guerrini, R.E. Kaplan, A. Gambardella, O.K. Steinlein, B.E. Grinton, J.T. Dean, L. Bordo, B.L. Hodgson, T. Yamamoto, J.C. Mulley, F. Zara and I.E. Scheffer, 2004. Benign familial neonatal-infantile seizures: Characterization of a new sodium channelopathy. Ann. Neurol., 55: 550-557. DOI: 10.1002/ana.20029.

6. Heron, S.E., K.M. Crossland, E. andermann, H.A. Phillips, A.J. Hall, A. Bleasel, M. Shevell, S. Mercho, M.H. Seni, M.C. Guiot, J.C. Mulley, S.F. Berkovic and I.E. Scheffer, 2002. Sodium channel defects in benign familial neonatalinfantile seizures. Lancet, 360: 851-852. DOI: 10.1016/S0140-6736(02)09968-3.

7. Catterall, W.A., 1996. Molecular properties of sodium and calcium channels. J. Bioenerg. Biomembr, 28: 219-230. DOI: 10.1007/BF02110697

8. Vanoye, C.G., C. Lossin, T.H. Rhodes and A.L. George Jr, 2006. Single-channel properties of HumanNaV1.1 and mechanism of channel dysfunction in SCN1A-associated epilepsy. J. Gen. Physiol., 127: 1-14. DOI: 10.1085/jgp.200509373.

9. Wallace, R.H., D.W. Wang, R. Singh, I.E. Scheffer, A.L. George, H.A. Phillips, K. Saar, A. Reis, E.W. Johnson, G.R. Sutherland, S.F. Berkovic and J.C. Mulley, 1998. Febrile seizures and generalized epilepsy associated with a mutation in the $\mathrm{Na}(1)$-channel beta-1 subunit gene SCN1B. Nat. Genet., 19: 366-370. DOI: 10.1016/j.neuroscience.2007.05.038.

10. Baulac, S., I. Gourfinkel-An, F. Picard, M. Rosenberg-Bourgin, J.F. Prud'homme, M. Baulac, A. Brice and E. LeGuern, 1999. A second locus for familial generalized epilepsy with febrile seizures plus maps to chromosome 2q21q33. J. Hum. Genet., 65: 1078-1085. http://www.pubmedcentral.nih.gov/articlerender.fc gi? artid=1288241.

11. Escayg, A., B.T. MacDonald, M.H. Meisler, S. Baulac, G. Huberfeld, I. An-Gourfinkel, A. Brice, E. LeGuern, B. Moulard, D. Chaigne, C. Buresi and A. Malafosse, 2000. Mutations of SCN1A, encoding a neuronal sodium channel, in two families with GEFS+2. Nat. Genet., 24: 343-545. DOI: 10.1038/74159.
12. Pfeiffer, A., J. Thompson, C. Charlier, B. Otterud, T. Varvil, C. Pappas, C. Barniz, K. Gruenthal, R. Khhn and M. Leppert, 1999. A locus for febrile seizures (FEB3) maps to chromosome 2q23-24. Ann. Neurol., 46: 671-678. DOI: 10.1002/15318249(199910)46:4<671: AID-ANA20>3.0.CO;2-5.

13. Jenke, M., A. Sánchez, F. Monje, W. Stühmer, R.M. Weseloh and L.A. Pardo, 2003. C-terminal domains implicated in the functional surface expression of potassium channels. EMBO J., 22: 395-403. DOI: 10.1093/emboj/cdg035.

14. Schwake, M., D. Athanasiadu, C. Beimgraben, J. Blanz, C. Beck, T.J. Jentsch, P. Saftig and T. Friedrich, 2006. Structural determinants of Mtype KCNQ (Kv7) $\mathrm{K}+$ channel assembly. Neuroscience, 26: 3757-3766. DOI: 10.1523/JNEUROSCI.5017-05.2006.

15. Leppert, M., V.E. Anderson, T. Quattlebaum, D. Stauffer, P. O'Connell, Y. Nakamura, J.M. Lalouel and R. White, 1989. Benign familial neonatal convulsions linked to genetic markers on chromosome 20. Nature, 337: 647-648. DOI: $10.1038 / 337647 \mathrm{a} 0$.

16. Wang, H.S., Z. Pan, W. Shi, B.S. Brown, R.S. Wymore, I.S. Cohen, J.E. Dixon and D. McKinnon, 1998. KCNQ2 and KCNQ3 potassium channel subunits: Molecular correlates of the M-channel. Science, 282: 1890-1893. DOI: 10.1126/science. 282.5395 .1890 .

17. Meves, H., J.R. Schwarz and I. Wulfsen, 1999. Separation of M-like current and ERG current in NG108-15 cells. Br. J. Pharmacol., 127: 1213-1223. DOI: 10.1038/sj.bjp.0702642.

18. Lucarini, N., A. Verrotti, V. Napolioni, G. Bosco and P. Curatolo, 2007. Genetic polymorphisms and idiopathic generalized epilepsies. Pediat. Neurol., 37: 158-163. DOI: 10.1016/j.pediatrneurol.2007.06.001.

19. Singh, N.A., P. Westenskow, C. Charlier, C. Pappas, J. Leslie, J. Dillon, V.E. anderson, M.C. Sanguinetti and M.F. Leppert, 2003. KCNQ2 and KCNQ3 potassium channel genes in benign familial neonatal convulsions: Expansion of the functional and mutation spectrum. Brain, 126: 2726-2737. DOI: 10.1093/brain/awg286.

20. Schwake, M., M. Pusch, T. Kharkovets and T.J. Jentsch, 2000. Surface expression and single channel properties of KCNQ2/KCNQ3, M-type K+ channels involved in epilepsy. J. Biol. Chem., 275: 13343-13348. http://www.jbc.org/cgi/ content/full/275/18/13343.

21. Schwake, M., T.J. Jentsch, Jentsch and T.I. Friedrich, 2003. A carboxyterminal domain determines the subunit specificity of KCNQ K+ channel assembly. EMBO Rep., 4: 76-81. DOI: 10.1038/sj.embor.embor715. 
22. Yus-Najera, E., I. Santana-Castro and A. Villarroel, 2002. The identification and characterization of a noncontinuous calmodulinbinding site in noninactivating voltage-dependent KCNQ potassium channels. J. Biol. Chem., 277: 28545-28553. DOI: 10.1074/jbc.M204130200.

23. Hoshi, N., J.S. Zhang, M. Omaki, T. Takeuchi, S. Yokoyama, N. Wanaverbecq, L.K. Langeberg, Y. Yoneda, J.D. Scott, D.A. Brown and H. Higashida, 2003. AKAP150 signaling complex promotes suppression of the M-current by muscarinic agonists. Nat. Neurosci., 6: 564-571. http://www.ucl.ac.uk/npp/dab/Hoshi\%20et\%20al\% 202003.pdf.

24. Dolmetsch, R.E., U. Pajvani, K. Fife, J.M. Spotts and M.E. Greenberg, 2001. Signaling to the nucleus by an L-type calcium channel-calmodulin complex through the MAP kinase pathway. Science, 294: 333-339. DOI: 10.1126/science.1063395.

25. Fields, R.D., P.R. Lee and J.E. Cohen, 2005. Temporal integration of intracellular $\mathrm{Ca}^{2+}$ signaling networks in regulating gene expression by action potentials. Cell Calcium, 37: 433-442. DOI: 10.1016/j.ceca.2005.01.011.

26. Seagar, M. and M. Takahashi, 1998. Interactions between presynaptic calcium channels and proteins implicated in synaptic vesicle trafficking and exocytosis. J. Bioenerg. Biomembr., 30: 347-356. DOI: 10.1023/A: 1021937605818.

27. Spafford, J.D., J. Van Minnen, P. Larsen, A.B. Smit, N.I. Syed and G.W. Zamponi, 2004. Uncoupling of calcium channel alphal and beta subunits in developing neurons. J. Biol. Chem., 279: 41157-41167. DOI:10.1074/jbc.M403781200

28. Wheeler, D.B., A. Randall and R.W. Tsien, 1996. Changes in action potential duration alter reliance of excitatory synaptic transmission on multiple types of $\mathrm{Ca}^{2+}$ channels in rat hippocampus. J. Neurosci., 16: 2226-2237. http://www.jneurosci. org/cgi/content/full/17/11/4066.

29. Perez-Reyes, E., 2003. Molecular physiology of low-voltage-activated t-type calcium channels. Physiol. Rev., 83: 117-161. DOI: 10.1152/physrev.00018.2002 0031-9333/03.

30. Weick, J.P., R.D. Groth, A.L. Isaksen and P.G. Mermelstein, 2003. Interactions with PDZ proteins are required for L-type calcium channels to activate cAMP response element-binding protein-dependent gene expression. J. Neurosci., 23: 3446-3456. http://www.jneurosci.org/ cgi/content/full/23/8/3446.

31. Westenbroek, R.E., T. Sakurai, E.M. Elliott, J.W. Hell, T.V. Starr, T.P. Snutch and W.A. Catterall, 1995. Immunochemical identification and subcellular distribution of the alpha 1A subunits of brain calcium channels. J. Neurosci., 15: 6403-6418. DOI: 10.1016/01680102(96)88605-6.
32. Wheeler, D.B., A. Randall and R.W. Tsien, 1996. Changes in action potential duration alter reliance of excitatory synaptic transmission on multiple types of $\mathrm{Ca}^{2+}$ channels in rat hippocampus. J. Neurosci., 16: 2226-2237. http://www. jneurosci.org/cgi/reprint/16/7/2226.

33. Burke, S.P., M.E. Adams and C.P. Taylor, 1993. Inhibition of endogenous glutamate release from hippocampal tissue by $\mathrm{Ca}^{2+}$ channel toxins. Eur. J. Pharmacol., 238: 383-386.

34. Caddick, S.J., C. Wang, C.F. Fletcher, N.A. Jenkins, N.G. Copeland and D.A. Hosford, 1999. Excitatory but not inhibitory synaptic transmission is reduced in lethargic (Cacnb4 (lh)) and tottering (Cacnalatg) mouse thalami. J. Neurophysiol., 81: 2066-2074. http://jn.physiology. org/cgi/content/full/81/5/2066.

35. Doroshenko, P.A., A. Woppmann, G. Miljanich and G.J. Augustine, 1997. Pharmacologically distinct presynaptic calcium channels in cerebellar excitatory and inhibitory synapses. Neuropharmacology, 36 : $865-872$. DOI: 10.1016/S0028-3908(97)00032-4.

36. Leenders, A.G., A.M. van den Maagdenberg, F.H. Lopes da Silva, Z.H. Sheng, P.C. Molenaar and W.E. Ghijsen, 2002. Neurotransmitter release from tottering mice nerve terminals with reduced expression of mutated P-and Q-type $\mathrm{Ca}^{2+}$-channels. Eur. J. Neurosci., 15: 13-18. DOI: 10.1046/j.0953816x.2001.01839.x.

37. Bourinet, E., T.W. Soong, K. Sutton, S. Slaymaker, E. Mathews, A. Monteil, G.W. Zamponi, J. Nargeot and Snutch TP. 1999. Splicing of alpha 1A subunit gene generates phenotypic variants of P-and Q-type calcium channels. Nat. Neurosc., 2: 407-415. DOI: $10.1038 / 8070$.

38. Chemin, J., A. Monteil, E. Perez-Reyes, E. Bourinet, J. Nargeot and P. Lory, 2002. Specific contribution of human t-type calcium channel isotypes (alpha (1G), alpha (1H) and alpha (1I)) to neuronal excitability. J. Physiol., 540: 3-14. DOI: 10.1113/jphysiol.2001.013269.

39. Tsakiridou, E., L. Bertollini, M. de Curtis, G. Avanzini and H.C. Pape, 1995. Selective increase in t-type calcium conductance of reticular thalamic neurons in a rat model of absence epilepsy. J. Neurosci., 15: 3110-3117. http://www.jneurosci.org/cgi/reprint/15/4/3110.

40. Kim, D., I. Song, S. Keum, T. Lee, M.J. Jeong, S.S. Kim, M.W. McEnery and H.S. Shin, 2001. Lack of the burst firing of thalamocortical relay neurons and resistance to absence seizures in mice lacking alpha (1G) T-type $\mathrm{Ca}(2+)$ channels. Neuron, 31: 35-45. DOI: 10.1016/S08966273(01)00343-9. 
41. Sutton, K.G., J.E. McRory, H. Guthrie, T.H. Murphy and T.P. Snutch, 2006. P/Q-type calcium channels mediate the activity-dependent feedback of syntaxin-1A. Nature, 401: 800-804. DOI: $10.1038 / 44586$.

42. Zhong, X., J.R. Liu, J.W. Kyle, D.A. Hanck and W.S. Agnew, 2006. A profile of alternative RNA splicing and transcript variation of CACNA1H, a human T-channel gene candidate for idiopathic generalized epilepsies. Hum. Mol. Genet., 15: 1497-1512. DOI: 10.1093/hmg/ddl068.

43. Jones, S.W., 1998. Overview of voltage-dependent calcium channels. J. Bioenerg. Biomembr., 30, 299-312. DOI:10.1023/A:1021977304001
44. Khosravani, H. and G.W. Zamponi, 2006. Voltagegated calcium channels and idiopathic generalized epilepsies. Physiol. Rev., 86: 941-966. DOI: 10.1152/physrev.00002.2006 0031-9333/06.

45. Moulard, B., F. Picard, S. le Hellard, C. Agulhon, S. Weiland, I. Favre, S. Bertrand, A. Malafosse and D. Bertrand, 20o1. Ion channel variation causes epilepsies. Brain Res. Rev., 36: 275-284. DOI: 10.1016/S0165-0173(01)00104-7.

46. Hirose, S., M. Okada, S. Kaneko and A. Mitsudome, 2000. Are some idiopathic epilepsies disorders of ion channels? A working hypothesis. Epilepsy Res., 41: 191-204. DOI: 10.1016/S09201211(00)00141-8/. 